\title{
A Management Maturity Model (MMM) for project-based organisational performance assessment
}

\author{
Craig Langston ${ }^{1}$ and Amir Naser Ghanbaripour ${ }^{2}$ \\ ${ }^{1}$ Bond University, Australia \\ ${ }^{2}$ Iran University of Science and Technology
}

\begin{abstract}
Common sense suggests that organisations are more likely to deliver successful projects if they have systems in place that reflect a mature project environment based on a culture of continuous improvement. This paper develops and discusses a Management Maturity Model (MMM) to assess the maturity of project management organisations through a customisable, systematic, strategic and practical methodology inspired from the seminal work of Darwin, Deming, Drucker and Daniel. The model presented is relevant to organisations, such as construction and engineering companies, that prefer to use the Project Management Body of Knowledge (PMBOK ${ }^{\mathrm{TM}}$ Guide) published by the Project Management Institute (PMI), but without the disadvantages of excessive time and cost commitments and a 'one size fits all' approach linked to rigid increments of maturity. It offers a game-changing advance in the application of projectbased organisational performance assessment compared to existing market solutions that are unnecessarily complex. The feasibility of MMM is field-tested using a medium-sized data centre infrastructure firm in Tehran.
\end{abstract}

Keywords: Project management, delivery success, organisation maturity modelling, PMBOK

Paper type: Research article

\section{Introduction}

All kinds of organisations, whether they be government agencies, private companies, charitable institutions or other collectives, spend time and effort to define their short, medium and long term objectives and the strategies that help them to be achieved (Demir and Kocabaş, 2010). The essence of project management is a direct outcome of what is the required scope of work and how well it is implemented (Silva et al., 2014). The contemporary need for project management, and the contribution that is possible from deploying a structured methodology, regardless of industry sector or discipline, is well documented. Project management has become both a key activity of organisational management and has enabled success, balance and harmony to be realised by global organisations (Hutson, 1997).

The definition of organisational maturity refers to operations that are in perfect synergy to achieve strategic objectives (Silva et al., 2014). Maturity models are considered to be tools that simulate specific aspects of capability and define the qualitative attributes that characterise competence at a particular level of performance (Demir and Kocabaş, 2010). These levels are typically sequential (Kohlegger et al., 2009). The origins of maturity models lie in the discipline of total quality management. They require a thorough understanding of an organisation's current

Copyright: Construction Economics and Building 2016. (C) 2016 Craig Langston and Amir Naser Ghanbaripour. This is an Open Access article distributed under the terms of the Creative Commons Attribution 4.0 Unported (CC BY 4.0) License (https://creativecommons.org/licenses/by/4.0/), allowing third parties to copy and redistribute the material in any medium or format and to remix, transform, and build upon the material for any purpose, even commercially, provided the original work is properly cited and states its license.

Citation: Langston, C. and Ghanbaripour, A.N. 2016. A Management Maturity Model (MMM) for project-based organisational performance assessment. Construction Economics and Building, 16(4), 68-85. DOI: http://dx.doi.org/10.5130/AJCEB.v16i4.5028

Corresponding author: Craig Langston; Email - clangsto@bond.edu.au

Publisher: University of Technology Sydney (UTS) ePress 
strategic position and where it aims to be in the future (Brookes and Clark, 2009). A maturity model provides a framework for systematic and continuous performance improvement.

Organisations are considered more likely to deliver successful projects if they have systems in place that reflect a mature project management environment based on a culture of continuous improvement (Crawford, 2011). Over the years research has been undertaken to develop frameworks that objectively measure organisational maturity (Cooke-Davies, 2004; Nesensohn et al., 2014). Popular frameworks in widespread use are generally complex and require a high degree of expertise and time when deployed in practice.

Nesensohn et al. (2014) found that over the past two decades there has been a rapid growth in publications about organisational maturity. Based on a search of four key databases (i.e. Business Source Complete; Emerald; Scopus; Discover) from 1990 to 2013, they found that the number of relevant articles per database has increased every year. There has been a simultaneous growth in maturity models over this period.

The aim of this paper is to set out a management maturity model based on the plan-do-check-act (PDCA) cycle to assess the maturity and performance of organisations in project management environments. This includes a review of relevant literature, reflection of criticisms, model development based on a unique conceptual approach, and field testing of this proposed solution in a real organisation, followed by discussion of implementation feedback and final conclusions.

\section{Literature review}

The achievement of consistent project management excellence is assisted by mature organisational systems and processes. The understanding of maturity, however, is often a subjective concept (Pretorius et al., 2012). Maturity models typically have a conceptual underpinning with constituent components that define the progressive development of capabilities, and ideally outline the processes that organisations could implement to achieve a more mature state (PMI, 2013). Maturity improvements require a concerted effort of continuous review and reflection at an organisational management level.

It should be noted that maturity models, like the discipline of project management itself, apply generically to any industry sector. For example, no compelling consensus was found in the literature that organisations undertaking engineering and construction projects require a bespoke solution. Some models have certainly emerged from a particular sector, such as software development, but their subsequent application has been demonstrated over time to have a much broader appeal.

There are now a number of maturity models operating within a range of business management fields, and in particular within the discipline of project management. The three main players in project management are discussed below.

\section{Capability Maturity Model Integration (CMMI)}

The Capability Maturity Model Integration (CMMI) project had its origins in a number of other tools that were developed from 1986 and were combined together in 1993 to form a single integrated tool (de Souza and Gomes, 2015). According to the CMMI Institute, over 10,500 individual CMMI appraisals have now been undertaken globally since 2007, making it the most successful maturity tool available. The CMMI Institute operates through a network of CMMI partners, which comprise trained and certified organisations and individuals providing official training programs, appraisals and other consulting services. The CMMI Institute Partner Network enables global reach to organisational clients and is the only avenue for authentic CMMI services outside of the institute itself (http:// cmmiinstitute.com/about-cmmi-institute). 
Building on an organisation's business performance objectives, CMMI provides a set of practices for improving processes, resulting in a continuous improvement system that paves the way for better operations and performance. CMMI applies to organisations that undertake software development, systems engineering and product development through the use of a single tool to assess maturity or capability, and provides direction while developing more sophisticated processes (Staples et al., 2007; Pane and Sarno, 2015). There are five maturity levels used in the 'staged' representation of CMMI:

1. Initial: Processes are unpredictable, poorly controlled and reactive

2. Managed: Processes are characterised for projects and are often reactive

3. Defined: Processes are characterised for the organisation and are proactive

4. Quantitatively managed: Processes are measured and controlled

5. Optimising: There is a focus on process improvement

An immature organisation would display characteristics such as process improvisation, approved processes being ignored, reactive as opposed to proactive decisions, unrealistic budget and schedule constraints, quality sacrificed for schedule, and no objective measure of quality. In contrast, the characteristics of a mature organisation include inter-group communication and coordination, work accomplished according to plan, practices consistent with processes, processes updated as necessary, well-defined roles/responsibilities, and formal commitment from management.

CMMI can also be used as 'continuous' representation, where six capability levels apply instead. In this case, 'level 1: initial' is subdivided into 'level 0: incomplete' and 'level 1: performed'. The remaining levels are the same. There is little significance between the meaning attached to maturity and capability.

Some studies state that there is a problem with the adoption of CMMI by organisations, and facilitation of the assessment is required to avoid wasting resources (Hardgrave and Armstrong, 2005; Staples and Niazi, 2010; Allué et al., 2013). According to Allué et al. (2013), one way of achieving facilitation is to provide organisations with tools or software products that make the adoption of CMMI easier. Few tools support all of the types of CMMI-related activities however as the support level that is provided is often limited, and a tool's ability to be customised according to the users' needs is quite small (Musat et al., 2010). CMMI is compatible with the AGILE project management methodology (Jiang et al., 2004).

\section{Portfolio, Program \& Project Management Maturity Model (P3M3)}

The Office of Government Commerce (OGC) fostered the development of a government maturity standard called the Portfolio, Program and Project Management Maturity Model (P3M3), aligned to the PRINCE2 methodology (González et al., 2007). According to Sowden et al. (2008:8), "P3M3 is not simply about isolated, here-and-now assessments - it also acts as a roadmap for ongoing improvement and progression towards realistic and achievable goals that are suitable for your business needs and aspirations". González et al. (2007) states that P3M3 focuses on the addition of portfolio and program management domains to earlier versions of the model, helping to expand emerging processes of project complexity that contribute to overall success. The levels of maturity in P3M3 are effectively identical to those for CMMI, and are described in Table 1.

P3M3, like PRINCE2, is a joint venture between OGC and Axelos and has a strong support base in the United Kingdom. It is built on seven process-related perspectives that exist in project, program and portfolio domains and is assessed at five levels of increasing maturity (https://www.axelos.com/best-practice-solutions/p3m3/what-is-p3m3). These perspectives are:

1. Organisational governance

2. Management control 
3. Benefits management

4. Risk management

5. Stakeholder management

6. Finance management

7. Resource management

Young et al. (2014:220) argue that one deficiency of the P3M3 model is that it "uses a single number to represent maturity at the project, program and portfolio level, with this number being the lowest score in either generic attributes or the process perspectives across each sub-model [...] the single number reported is therefore misleading and will generally report a lower level of maturity than what is present in an organisation, not only painting a poorer picture than what might exist [... but] disregarding the relative closeness of the next higher level". Another shortcoming they mention is that the 'generic attributes' evaluated in all three P3M3 domains are claimed as essential to achieving improvement in project management maturity. It is doubtful however whether these generic attributes are appropriate for program and portfolio management domains, which are typically more complex than standalone project management (Artto et al., 2009; Young et al., 2014).

Table 1: P3M3 maturity levels (Sowden et al., 2008)

\begin{tabular}{|c|c|c|c|}
\hline $\begin{array}{l}\text { Maturity } \\
\text { Level }\end{array}$ & Portfolio Management & Program Management & Project Management \\
\hline $\begin{array}{l}\text { Level 1: } \\
\text { awareness } \\
\text { of process }\end{array}$ & $\begin{array}{l}\text { Does the organisation's Executive } \\
\text { Board recognise programs and } \\
\text { projects, and maintain an informal } \\
\text { list of its investments in programs } \\
\text { and projects? }\end{array}$ & $\begin{array}{l}\text { Does the organisation recognise } \\
\text { programs and run them } \\
\text { differently from projects? }\end{array}$ & $\begin{array}{l}\text { Does the organisation recognise } \\
\text { projects and run them differently } \\
\text { from its ongoing business? }\end{array}$ \\
\hline $\begin{array}{l}\text { Level 2: } \\
\text { repeatable } \\
\text { process }\end{array}$ & $\begin{array}{l}\text { Does the organisation ensure that } \\
\text { each program and/or project in its } \\
\text { portfolio is run with its own } \\
\text { processes and procedures to a } \\
\text { minimum specified standard? }\end{array}$ & $\begin{array}{l}\text { Does the organisation ensure that } \\
\text { each program is run with its own } \\
\text { processes and procedures to a } \\
\text { minimum specified standard? }\end{array}$ & $\begin{array}{l}\text { Does the organisation ensure that } \\
\text { each project is run with its own } \\
\text { processes and procedures to a } \\
\text { minimum specified standard? }\end{array}$ \\
\hline $\begin{array}{l}\text { Level 3: } \\
\text { defined } \\
\text { process }\end{array}$ & $\begin{array}{l}\text { Does the organisation have its own } \\
\text { centrally controlled program and } \\
\text { project processes and can individual } \\
\text { programs and projects flex within } \\
\text { these processes to suit particular } \\
\text { programs and/or projects. Does the } \\
\text { organisation have its own portfolio } \\
\text { management process? }\end{array}$ & $\begin{array}{l}\text { Does the organisation have its } \\
\text { own centrally controlled program } \\
\text { processes and can individual } \\
\text { programs flex within these } \\
\text { processes to suit the particular } \\
\text { program? }\end{array}$ & $\begin{array}{l}\text { Does the organisation have its own } \\
\text { centrally controlled project processes } \\
\text { and can individual projects flex } \\
\text { within these processes to suit the } \\
\text { particular project? }\end{array}$ \\
\hline $\begin{array}{l}\text { Level 4: } \\
\text { managed } \\
\text { process }\end{array}$ & $\begin{array}{l}\text { Does the organisation obtain and } \\
\text { retain specific management metrics } \\
\text { on its whole portfolio of programs } \\
\text { and projects as a means of } \\
\text { predicting future performance? } \\
\text { Does the organisation assess its } \\
\text { capacity to manage programs and } \\
\text { projects and prioritise them } \\
\text { accordingly? }\end{array}$ & $\begin{array}{l}\text { Does the organisation obtain and } \\
\text { retain specific measurements on } \\
\text { its program management } \\
\text { performance and run a quality } \\
\text { management organisation to } \\
\text { better predict future } \\
\text { performance? }\end{array}$ & $\begin{array}{l}\text { Does the organisation obtain and } \\
\text { retain specific measurements on its } \\
\text { project management performance } \\
\text { and run a quality management } \\
\text { organisation to better predict future } \\
\text { performance? }\end{array}$ \\
\hline $\begin{array}{l}\text { Level } 5: \\
\text { optimised } \\
\text { process }\end{array}$ & $\begin{array}{l}\text { Does the organisation undertake } \\
\text { continuous process improvement } \\
\text { with proactive problem and } \\
\text { technology management for the } \\
\text { portfolio in order to improve its } \\
\text { ability to depict performance over } \\
\text { time and optimise processes? }\end{array}$ & $\begin{array}{l}\text { Does the organisation undertake } \\
\text { continuous process improvement } \\
\text { with proactive problem and } \\
\text { technology management for } \\
\text { programs in order to improve its } \\
\text { ability to depict performance } \\
\text { over time and optimise } \\
\text { processes? }\end{array}$ & $\begin{array}{l}\text { Does the organisation undertake } \\
\text { continuous process improvement } \\
\text { with proactive problem and } \\
\text { technology management for projects } \\
\text { in order to improve its ability to } \\
\text { depict performance over time and } \\
\text { optimise processes? }\end{array}$ \\
\hline
\end{tabular}

\section{Organisational Project Management Maturity Model (OPM3)}

Another important model used in the project management discipline is OPM3. Developed by a team of volunteers from the PMI between 1998 and 2013, it is suitable for organisations of any 
size, location or practice environment. It aims to enumerate the level of maturity of projects and practices, based on best practices as a methodology for assessment. Similar to P3M3, it sets out requirements to assist in the development of better capabilities that underpin projects, programs and portfolios and assist organisations to realise strategic objectives through the delivery of successful outcomes (PMI, 2013; Silva et al., 2014).

This model supports both continuous process improvement to diagnose existing organisational systems, and uniquely highlights potential problems or deficiencies including the detailed design of necessary improvements (Fahrenkrog et al., 2003). It is aligned specifically to the widely recognised PMBOK methodology. OPM3 compares organisational activities with a large number of standardised best practices, measuring them in project, program and portfolio management contexts by examining capabilities and related outcomes. Organisations are then classified into four levels of maturity development, not five as embedded in CMMI and P3M3, for each process area in each domain (Pinto and Williams, 2013):

1. Standardise: Structured processes are adopted

2. Measure: Data is used to evaluate process performance

3. Control: Control plan developed for measures

4. Continuously improve: Processes are optimised

Cooke-Davies (2004) state that the basic 'building blocks' of OPM3 are:

1. Use of best practices related to organisational project management

2. Core capabilities that are needed to support the achievement of each best practice outcome

3. Observable evidence that attests to the existence of specific capabilities that are routinely applied within an organisation

4. Key performance indicators (KPIs) and other metrics that provide a basis for objective outcome measurement

5. Pathways that identify the capabilities that aggregate to attainment of relevant best practice outcomes

Importantly, OPM3 creates and advocates the critical connection between organisational strategy and successful projects, as illustrated in Figure 1.

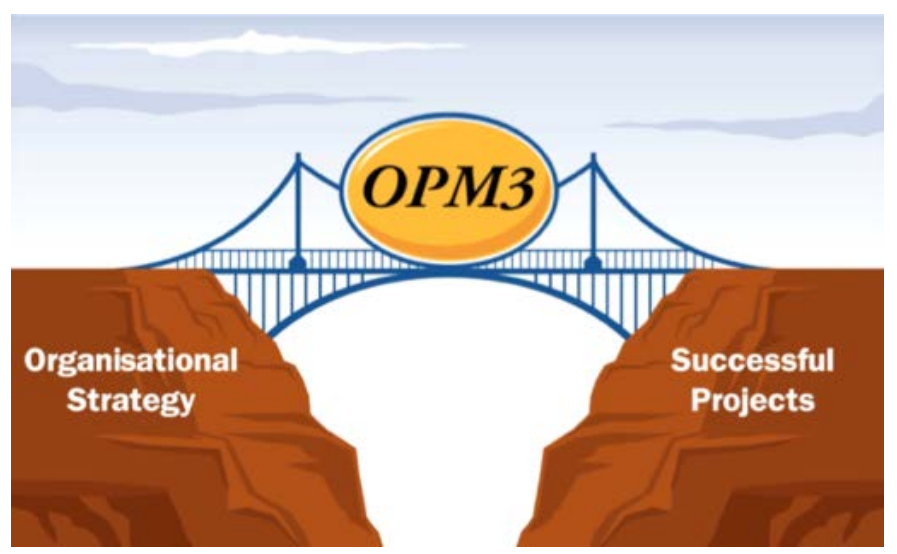

Figure 1: Core OPM3 philosophy (PMI, 2013)

OPM3 is by far the most sophisticated of the identified maturity models in the discipline of project management, but also the most resource intensive (Hillson, 2003; Cooke-Davies, 2004; Backlund et al., 2014). Current maturity models are unlikely to ever be the 'silver bullet' that one might hope for because they typically:

1. Lack a well-researched and theoretical understanding of what is needed for successful project management outcomes 
2. Are founded on the assumption that there is an ideal path of development towards maturity that most organisations should pursue regardless of discipline area, project scope, competitive marketplace context or chosen strategy

3. Must walk a fine line "between the 'Scylla' of over-simplification and the 'Charybdis' of excessive complexity" (Cooke-Davies, 2004:1252)

OPM3 is currently under review and is the subject of deep unrest between some of the certified assessors and the PMI over the current direction and marketing of a product that comprises shared intellectual property. Without full access to the best practice standards, which are the heart of the model, assessors are unable to use this tool in practice. It is likely that in the years that lie ahead OPM3 will be significantly changed and possibly rebranded.

\section{Other models}

A number of other maturity models discovered online were also reviewed:

1. The Berkeley Project Management Maturity Model (PM2): http://www.ce.berkeley.edu/ ibbs/yhkwak/pmmaturity.html

2. Kerzner PM Maturity Assessment: http://www.iil.com/kpm3/default.asp

3. PM Solutions Project Management Maturity Model (PMMM): http://www.pmsolutions.com/resources/view/what-is-the-project-managementmaturity-model/

4. The SUKAD Seven Elements of Project Management Maturity (7Es): http://sukadway.sukad.com/project-management-maturity-model-overview)

5. Onemind: www.onemind.co.uk

6. Standardised Process Improvement for Construction Enterprises (SPICE): http://usir.salford.ac.uk/9965/1/280_Jeong_KSStructured_Process_Improvement.pdf

7. IPMA Delta Module O (Organisation): http://www.ipma.world/certification/certifyorganisations/deltacompetence-classes/

\section{General criticisms}

One of the criticisms of applying the current models in organisations is the focus on explicit project management knowledge areas rather than intangible assets, which are less obvious but nevertheless contribute to a mature project management capability (Jugdev and Thomas, 2002). Intangible assets include context-specific outcomes such as customer involvement and implicit human factors including creativity, integrity and trust (Pasian et al., 2012; Backlund et al., 2014). Another problem with many models is the complexity of their frameworks, which may prevent potential users to implement them on the basis of time and cost commitment (Crawford, 2011).

Jugdev and Thomas (2002) also summarised some common criticisms of maturity models as comprising:

1. The models are mostly inflexible to change and ongoing improvements and are not able to address specific areas of specialisation

2. The models are often orientated towards identification of problems rather than solving problems

3. The models do not take account of the rapid pace of change and emerging technologies and innovative processes or practices adopted by organisations over time

4. The structured levels of maturity models do not propose sufficient detail to assess progress achievement

5. The models methodologies are largely mono-disciplined, disconnected from practice, and at times overwhelming

6. The models mostly ignore the human resource or operational aspects 
Maturity models often have a limited theoretical basis and lack conceptual underpinning (Backlund et al., 2014). A major research project by Thomas and Mullaly (2008) into the benefit of project management identified the significance of 'fit' between implementation of projects and organisational strategy, including the impact of internal and external contexts. Mullaly and Thomas (2010) also highlight that this contradicts lessons from contingency theory, suggesting that different organisational configurations can be successful provided the strategies are consistent with their environment. In other words, maturity models need to provide a bridge between project success and organisational strategy. Crawford (2011:1) makes the following observation:

'Project management is now recognised as an organisational capability and there are numerous generic
'maturity' models providing one size fits all approaches to what is considered to be 'best practice'. Both
maturity models and best practices are problematic. Maturity models typically suggest that all firms must
strive to progressively achieve prescribed levels of practice across the same range of 'best' practices. But what
constitutes best practice for whom and under what circumstances? If we look at an organisation's project
management systems, although they may have similarities across firms, they are operating in different
contexts, driven by different strategies. What may be bestfor some may not be best for others."

The literature highlights a situation where the dominant market solutions to organisational maturity each have disadvantages that make them too rigid (one size fits all), deterministic (based on hierarchical assessment), misaligned to objectives (not strategic) and impractical (disconnect to project success). In addition, existing market solutions are complicated and resource intensive.

Given the above, it is suggested that an appropriate management maturity model should be customisable by organisations (i.e. able to evolve according to their changing environment over time), systematic in its assessment of organisational capabilities (i.e. continuous improvement framework), aligned to organisational strategy at the level of project, program and portfolio (i.e. management by objectives), and relevant to project delivery success in practice (i.e. use of measurable critical success factors). There is opportunity to align the model to the PMBOK methodology given that OPM3 is the main player in this domain, yet OPM3 is extremely complicated, expensive (cost and time) and currently going through a tumultuous stage in its development.

\section{Proposed Management Maturity Model (MMM)}

Each of the key criteria mentioned above is examined in this section. Inspiration is drawn from the seminal work of Charles R. Darwin (1809-1882), W. Edwards Deming (1900-1993), Peter F. Drucker (1909-2005) and D. Ronald Daniel (1931-) for the design of the proposed Management Maturity Model (MMM). Intrinsic to the model's approach is the need for it to also be practical in the project management marketplace and hence capable of widespread adoption.

\section{Customisable}

The literature is clear that a 'one size fits all' approach to maturity assessment is flawed. Not only are organisations different, but they also operate in a wide range of industries that themselves are at different stages of maturity. It has always been a core objective of maturity models to enable comparison of organisations in the context of benchmarking against 'best practice'. What constitutes best practice in one industry, however, may not be appropriate in another. It is also a barrier to adoption if competitive advantage is lost through disclosure of levels of immaturity that might affect reputation and market position. A more confidential way to benchmark performance needs to be found.

Organisations evolve over time, and the strength of their capabilities dictates whether they are successful or unsuccessful. Maturity assessment needs to provide guidance on positive improvement and fix weaknesses that might lead to poor performance. 
Charles Darwin is renown for his contribution to evolution theory. His research established that all species of life have descended from common ancestors over time. His scientific theory was that this branching pattern of evolution resulted from a process of natural selection, in which the struggle to survive is similar to selective breeding programs. Darwin published his theory of evolution together with compelling field evidence in his book On the Origin of Species (Darwin, 1859). By the 1870s, the scientific community and a significant proportion of the general public believed evolution was indeed true, but it took many more years before a broad consensus emerged that natural selection was the basis of evolutionary improvement and capable of explaining the diversity of life on Earth. Darwin has been characterised as being one of the most influential people in human history.

Using this concept, organisations can be viewed as 'species' that evolve and diversify. This is not a function of maturation, but their agility to deal with external forces and trends within the environment in which they operate. These influences change over time. Best practice is also fluid.

Generic capabilities and standard criteria for mature systems and performance is limiting and inflexible. A better approach is for organisations to understand their journey of maturity over time by assessing their own core strategic objectives. Benchmarking with others can take place through the sharing of relevant organisational objectives used by market leaders or innovators that describe capabilities that are considered critical to success. Rather than comparing maturity levels to benchmark best practice, organisations adopt capabilities that are compatible with their individual structure and vision. Customisable core strategic objectives and organisational capabilities should be a key tenet in the process of maturity assessment.

\section{Systematic}

The literature is also clear that maturity assessment must be systematic and evidence-based. Maturity by definition is a process of continuous improvement from a state of relative simplicity (or naivety) to one of sophistication and rigour. This process needs to be capable of translation into measurable evidence at each stage of development. The level of maturity of an organisation is a function of the number of capabilities that can be observed to operate routinely at high levels of optimisation. The underlying systems put in place form the evidence of a mature process.

Continuous improvement is both sequential and cyclical. It is sequential because there are fundamental steps that must take place to reach higher levels of performance, and cyclical because organisations need to be able to learn from their performances in order to further improve the underlying processes and systematically pursue optimal outcomes (Wysocki, 2004).

Edwards Deming is credited with the well-respected plan-do-check-act (PDCA) continuous improvement cycle (Wood and Wood, 2005). The PDCA (see Figure 2) built on the work from Walter Shewhart's book Statistical Method from the Viewpoint of Quality Control (Shewhart, 1939) to produce the plan-do-study-act (PDSA) cycle. Nevertheless, Deming worked closely with Shewhart to develop the idea of continuous improvement as part of a system where feedback from the process and customer is evaluated against organisational goals (Moen and Norman, 2012). Deming is the father of the total quality management movement.

Continuous improvement can be applied to all management activities including project and performance management (Du et al., 2008). For example, in PMBOK (2013), the process groups are an example of PDCA, demonstrating that project management processes are similar to other business processes when it comes to continuous improvement. The PMBOK ${ }^{\mathrm{TM}}$ Guide adopts six process groups for projects - planning (plan), executing (do), monitoring (check) and controlling (act) - fitting within the context of initiating at the start and closing at the end of the project life cycle. The heart of the PMBOK methodology is closely aligned to PDCA. 


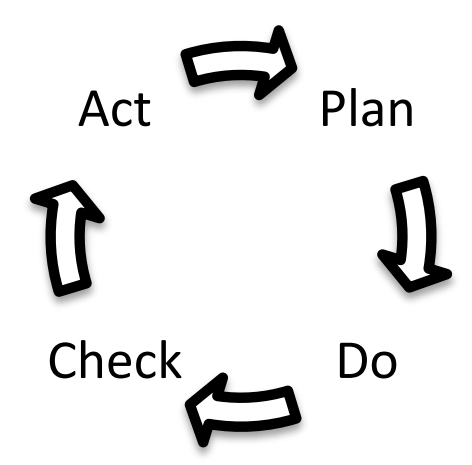

Figure 2: The PDCA continuous improvement cycle

For any project type, it is necessary to plan, do, check, and act. PDCA provides a robust and more tangible method for measuring maturity. The following analogy can be adopted for evidence-based assessment:

1. Plan: Establish targets

2. Do: Measure outcomes

3. Check: Assess performance

4. Act: Enhance protocols

Full maturity is reached when there is evidence of routine adoption of the above sequence in the underlying systems that support all of the appropriate organisational capabilities in the model. Rather than use a hierarchy of maturity levels, this approach highlights the need for nurturing a learning culture that aims to continuously improve (Stacey, 2003). A systematic cycle of organisational growth is thus supported.

\section{Strategic}

The literature refers to organisational capabilities as a framework in which maturity can be assessed. Capabilities are tied to core strategic objectives that are derived from a declared vision, mission and set of organisational values. The notion is that if capabilities are mature, then the achievement of organisational strategy is enhanced (Backlund et al., 2014). A large number of detailed capabilities, however, can inadvertently diminish their connection to strategy. It hence may be preferable to focus assessment on a smaller number of core capabilities (Nandyal, 2003).

The discipline of project management is commonly characterised as a combination of projects, programs (i.e. multiple aligned project) and portfolios (i.e. collections of projects and programs). It is likely that capabilities change and become more sophisticated on this continuum, and it provides an opportunity to demonstrate a maturation pathway from small scale (local projects) to large scale (global portfolios). In all cases, project management is achieved by the pursuit of objectives.

Peter Drucker is credited with the concept of management by objectives (MBO). His work contributed to the practical and philosophical foundations of the modern business corporation and he is frequently described as the founder of modern business management. He was a writer, academic, business consultant and self-acclaimed 'social ecologist' who explored the way that people interact and organise themselves. MBO arose from his book The Practice of Management (Drucker, 1954). It is a model of management that aims to improve organisational performance by clearly articulating strategic objectives that are accepted by both management and staff. According to the theory, participation in goal setting and the development of action plans leads to higher levels of commitment towards organisational success, as well as alignment of objectives across all parts of the business. 
There are countless ways to implement management by objectives in practice. One needs to set core strategic objectives and then break these down into progressive targets. Organisations that apply MBO frequently report higher rates for sales and improved worker productivity (http://smallbusiness.chron.com/examples-managerial-objectives-23790.html). Objectives can be defined at any level of an organisation - with collective or individual responsibility. Both enable the task at hand to be more attainable and help people to visualise what needs to be achieved and how this can happen. Objectives need quantifying and monitoring.

Organisational capabilities are similar to objectives and can be managed in the same way. These capabilities can be used to track performance in the quest to move from lower capability to higher capability over time (Dosi et al., 2000). Each capability requires a target goal to be established, outcomes to be measured, assessment of performance and the enhancement of systems and protocols where improvement is warranted.

\section{Practical}

The literature is clear that maturity models act as a bridge between organisational strategy and project success. What is not so clear is how to measure success in an objective and organisationwide manner. Cooke-Davies (2002) highlights confusion between terms such as 'project success' (doing the right project) and 'project management success' (doing the project right), and between 'success factors' (that lead to success) and 'success criteria' (that evaluate success). In the latter case, the list is long and criteria/factors are often specific to particular project types and client objectives (Davis, 2014). Success criteria (such as KPIs) and success factors (such as core project constraints) are commonly linked (Westerveld, 2003).

Ron Daniel developed the concept of success factors in the 1960s during his long-term role as Managing Director of McKinsey \& Co. The notion seems quite obvious: in any business environment certain factors will be critical to the achievement of success, and so logically if objectives associated with the factors are not realised, the business will fail - perhaps dramatically. The objectives are examples of success criteria, and often presented in the form of KPIs. Critical success factors were defined twenty year's later by John Rockart as success factors that are 'mission-critical' (Rockart, 1979; Bullen and Rockart, 1981). Daniel's work translates well to the discipline of project management where successful project delivery is always the main goal.

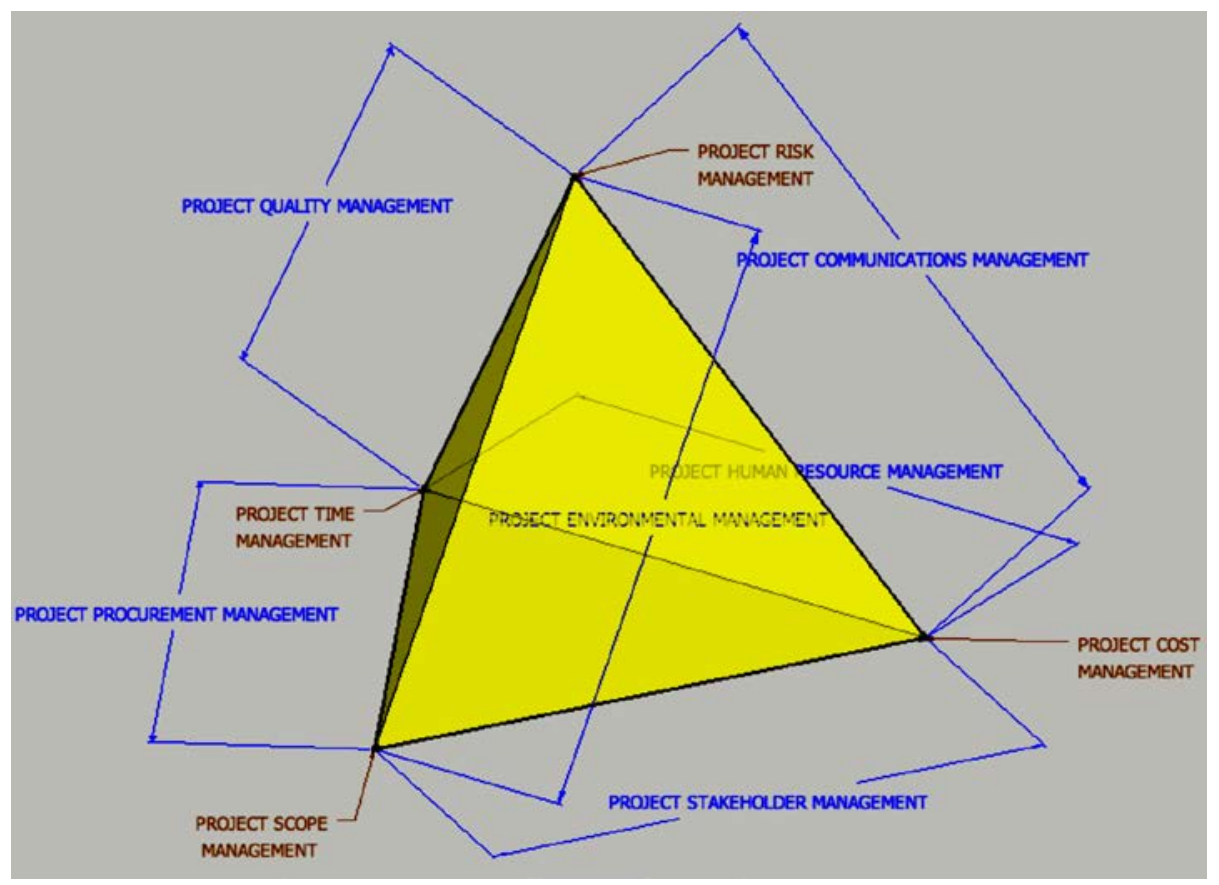

Figure 3: 3D Project integration model (Langston, 2013) 
Langston (2013) employs success factors and criteria to explain what successful projects might look like. His AIPM and IPMA award-winning model (shown in Figure 3) for describing project integration is presented as a tetrahedron containing all knowledge areas existing in the $P M B O K^{\mathrm{TM}}$ Guide (Fifth Edition), plus a new area of project environmental management that can recognise sustainability as an emerging aspect of modern project delivery (Ebbesen and Hope, 2013; Fernández-Sánchez and Rodríguez-López, 2010; Hwang and Ng, 2013). Langston contends his model can be deployed to measure the ability of project teams to deliver successful performances at all stages of the project life cycle. This is achieved through the identification of success factors (represented by the four vertices of the model) and success criteria (represented by the edges of the model). KPIs are derived from the model to describe the relationships between success factors. They are constructed so to be relevant to any project type as well as being capable of numeric measurement. Project Integration Management, a key knowledge area in the PMBOK ${ }^{\mathrm{TM}}$ Guide, is intended to ensure that the right balance between all parts of a project is achieved over the project life cycle, and is reflected in the 3D nature of the model itself.

This 3D project integration model includes six generic success criteria (KPIs) that are related to project delivery success (PDS). They comprise:

1. Value: This KPI is described as project scope divided by cost (objective: maximise). Value is assessed in the context of Project Stakeholder Management, including meeting specified expectations and fostering ongoing engagement. Scope is interpreted as an output and cost is interpreted as an input, therefore the more utility delivered per unit of cost the more value for money is realised.

2. Efficiency: This KPI is described as project cost divided by time (objective: maximise). Efficiency is assessed in the context of Project Human Resource Management, including leadership and team high performance. Cost is interpreted as an output (i.e. the value of work completed) and time is interpreted as an input, meaning that the more money expended per unit of time the more efficient is the project delivery process.

3. Speed: This KPI is described as project scope divided by time (objective: maximise). Speed is assessed in the context of Project Procurement Management, including outsourcing strategies and parallel supply chains. Scope is interpreted as an output, and time is interpreted as an input, such that the more utility provided per unit of time the faster the project delivery process.

4. Innovation: This KPI is described as project risk divided by cost (objective: maximise). Innovation is assessed in the context of Project Communications Management, including knowledge management and research-informed learning. Risk is interpreted as an output (innovation leads to development risks) and cost is interpreted as an input; therefore a higher level of risk per unit of cost reflects the search for better ways of doing things (i.e. extra risk is only warranted if competitive advantage is realised).

5. Complication: This KPI is described as project risk divided by time (objective: minimise). Complication (originally known as 'complexity') is assessed in the context of Project Quality Management, including being alert to excessive quality assurance paperwork and engineering over design. Risk is interpreted as an output and time is interpreted as an input, so a higher level of risk per unit of time is a sign of project difficulty that should be avoided during rollout.

6. Impact: This KPI is described as project risk divided by scope (objective: minimise). Impact is assessed in the context of Project Environmental Management, including awareness of adverse sustainability outcomes and unnecessary resource consumption. Risk is interpreted as an output and scope is interpreted as an input, meaning that a higher risk level per unit of utility reflects unwanted environmental disruption.

The key relationships between the four success factors (cost, time, scope and risk) and the six success criteria (value, efficiency, speed, innovation, complication and impact) are illustrated in 
Figure 4. A 2D representation of the model is provided for ease of comprehension, but it converts into a 3D tetrahedron by 'folding' along the dotted lines. Success factors are equally weighted and are shown in upper case.

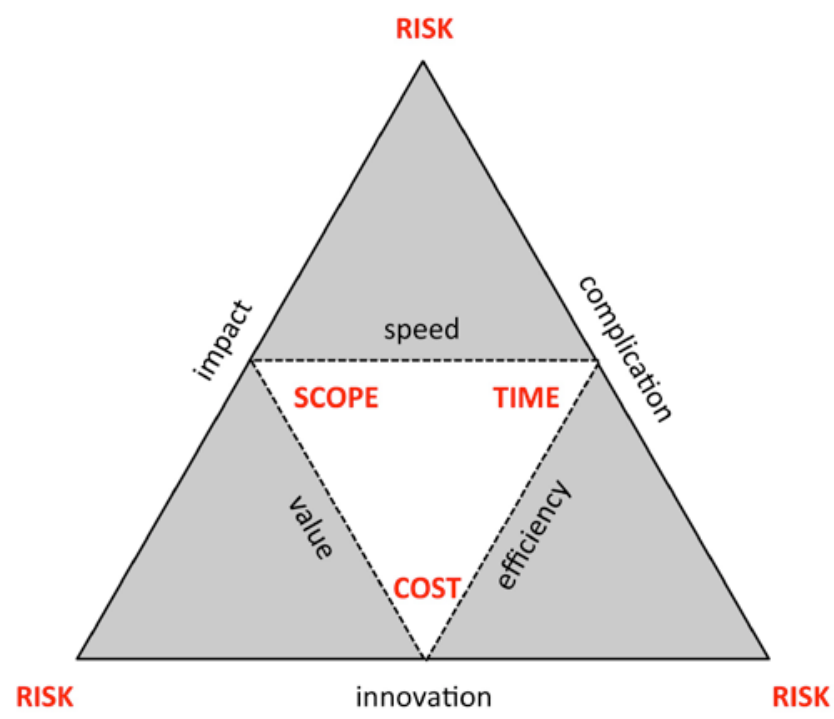

Figure 4: Success factors and success criteria (Langston, 2013)

Overall success (computed as the change in PDS between planned and actual performance) is given by the following formula (Langston, 2013):

$$
\text { Project Delivery Success }(P D S)=\frac{s^{3}}{c t r}
$$

where: $\mathrm{s}=$ scope baseline, $\mathrm{c}=$ cost baseline $\mathrm{t}=$ time baseline and $\mathrm{r}=$ risk baseline

\section{MMM design and testing}

Drawing on the above issues, a new approach for the assessment of organisation maturity is constructed. It is based on the six KPIs for project delivery success (value, efficiency, speed, innovation, complication and impact) plus an overall KPI to take account of the combined effect of the four success factors (scope, cost, time and risk). Continuous improvement based on PDCA is the means for assessing maturity. Core objectives and capabilities for project, program and portfolio domains can be identified. These are customisable and therefore can differ from one organisation to the next. The full model, shown in Figure 5, is tested in the field based on a medium-sized data centre infrastructure firm in Tehran. The data was collected anonymously and as such the firm is referred to as 'example organisation'.

The example organisation uses a management by project approach as the basis for its business model. Within its niche market it is considered a medium-sized firm and employs approximately 270 people. It had a turnover last financial year of US $\$ 45$ million and participated in numerous Iranian data centre projects as designer, supplier and constructor. The firm builds the data centre and then installs infrastructure using proprietary equipment sourced mainly from international suppliers.

The standard used for data centre design in the example organisation is ANSI/TIA942-2005 issued by the American Telecommunication Industry Association. In this standard, data centres are divided into different levels according to client requirements of reliability, infrastructure, construction structure, electric facilities and mechanical facilities (Ye et al., 2014). The example organisation is commissioned to design and build data centres according to client needs based on a rating/tier (1, 2, 3 or 4). A team of auditors certified by Uptime Institute (USA) perform monitoring compliance against the specified rating/tier. 


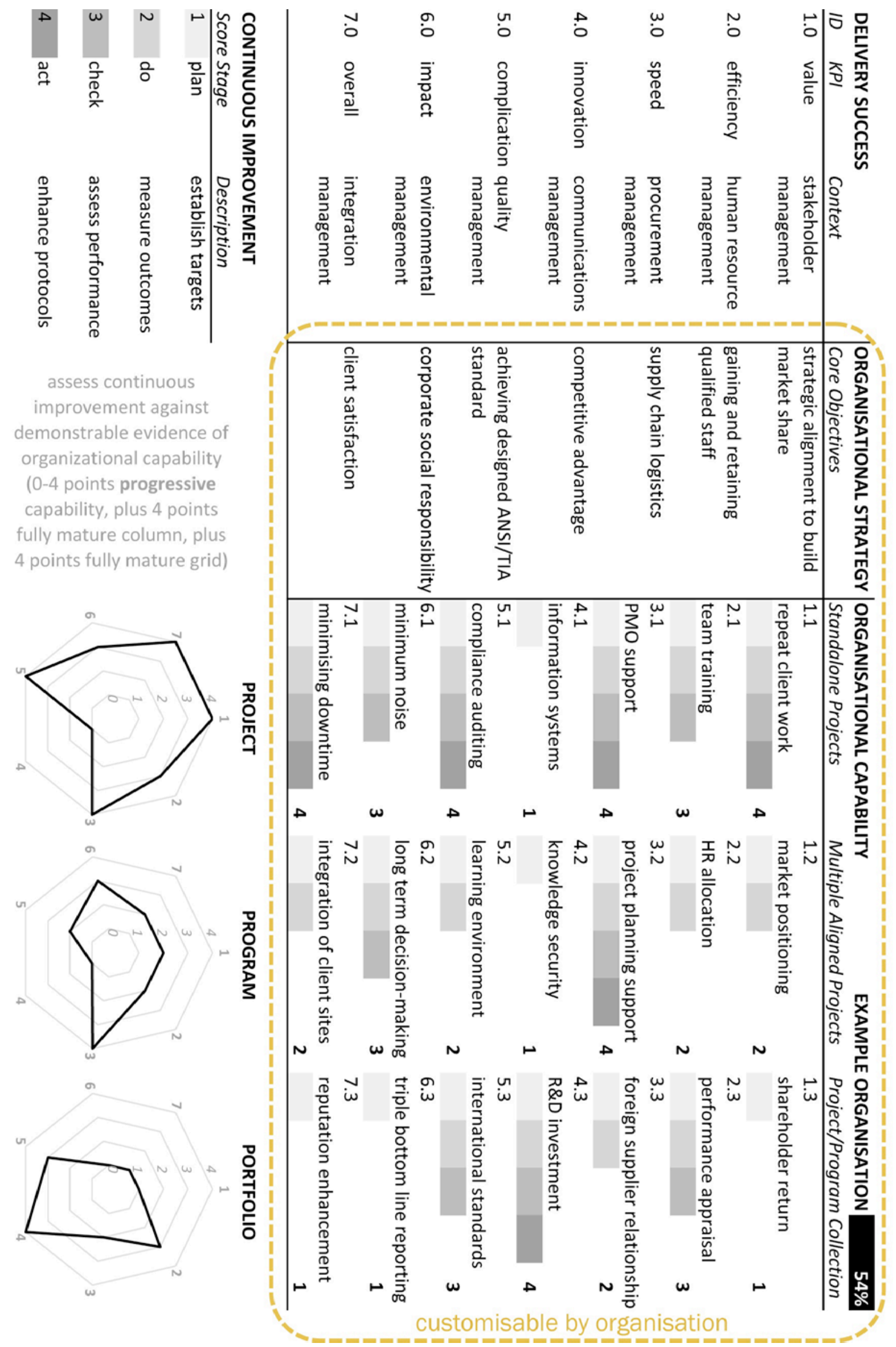

Figure 5: Proposed Management Maturity Model (MMM) 
The example organisation shared documents relating to organisational capabilities in action, and facilitated interview responses from the Chief Executive Officer (CEO) and various program and project managers who work at the firm. This access helped to identify the firm's core strategic objectives and relevant capabilities aligned to each KPI. Points were assigned only where demonstrable evidence could be observed. This evidence was recorded electronically and archived in a database underpinning the case study methodology.

To illustrate the process, the KPI of 'value' is discussed in more detail. Value is interpreted in the context of stakeholder management. The core objective for this KPI is identified as 'strategic alignment to build market share'. In other words, value is strengthened when the performance of a project, program or portfolio is aligned to the strategic vision, mission and values of the organisation. This objective is then broken down into capabilities that enable repeat client work (project level), market positioning (program level) and shareholder return (portfolio level). These three capabilities are in increasing order of complexity and are scored according to evidence of progressive PDCA improvement. Evidence of 'Plan' equals 1 point, 'Plan+Do' equals 2 points, 'Plan+Do+Check' equals 3 points, and 'Plan+Do+Check+Act' equals 4 points. Missing a step in the PDCA sequence disables the scoring of further steps. The evidence collected from the example organisation is shown in Figure 6.

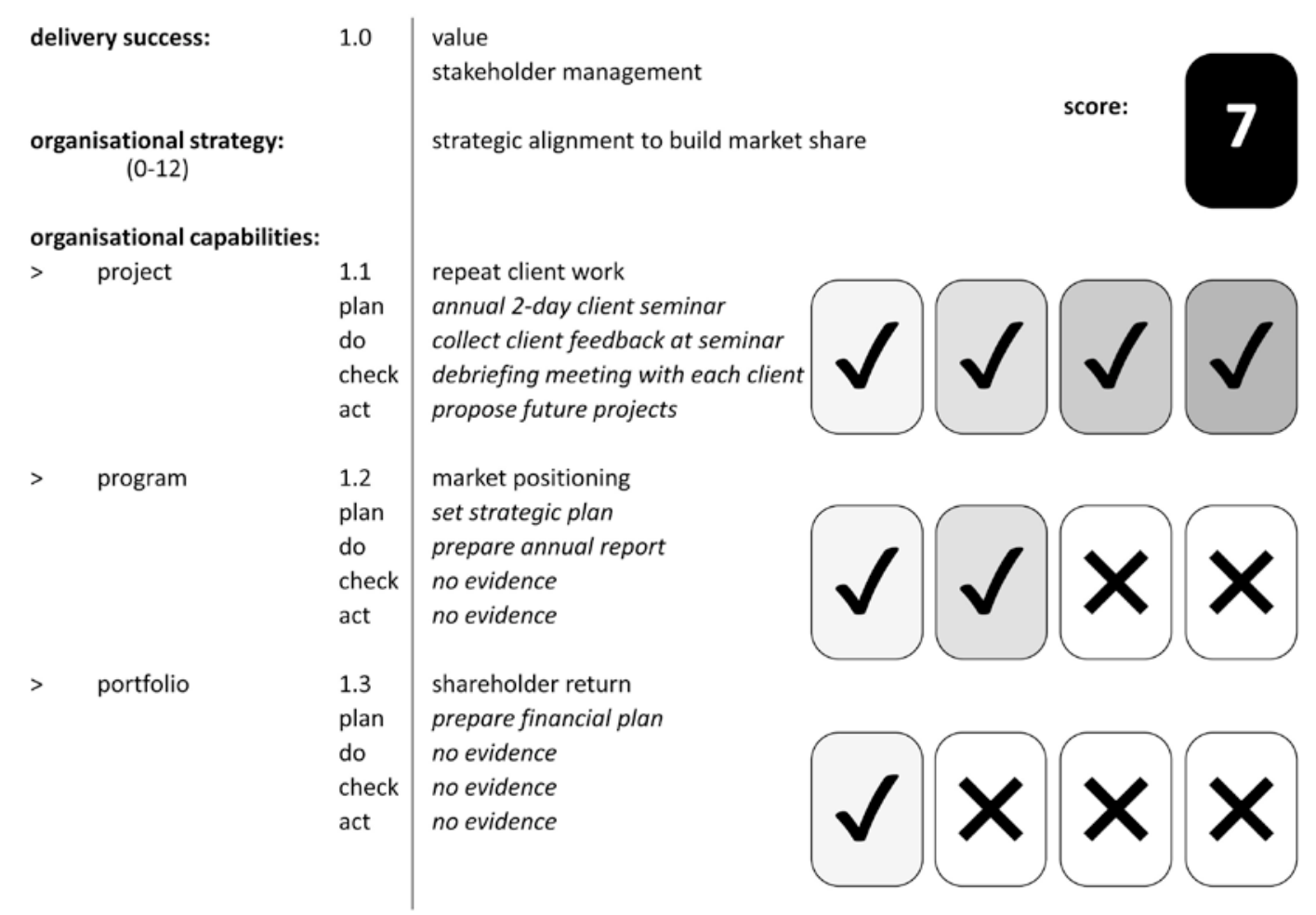

Figure 6: Example of identified case study evidence for 'value'

The maturity score for the example organisation is derived from a self-assessment process. Each domain can have a maximum score of 28. The radar diagrams show the level of maturity for project, program and portfolio domains, and the size of the mapped area gives a visual impression of where strengths and weaknesses lie (Jin et al., 2014). An extra 4 bonus points are awarded if a domain reaches this fully mature level. An extra 4 bonus points are awarded if all three domains are fully mature, and this would then equal 100 points overall (i.e. $100 \%$ maturity). 
The case study results show that the firm has a maturity score of $54 \%$ based on their own defined strategy and capabilities. The radar diagrams highlight the weakest performance is in the domain of portfolio management. The firm's Project Management Office (PMO) has contributed to the stronger performance at the level of individual projects. Results from discussions with key personnel identify that the most important objective when operating in the data centre infrastructure industry is to grow market share, and this is achieved by close alignment of all activities with overall organisational strategy. In order to obtain feedback on the case study findings, the $\mathrm{CEO}$ was later interviewed about the process and whether it was useful to the organisation. His key comments are listed below (translated from Persian):

Our company is one the most active firms in the data centre infrastructure business in Iran. We have done several ICT projects within this industry and our first priority is to meet customer expectations in order to get repeat work from them. We have hired and trained a number of professional experts to help us in this regard.

The other aspects in which I feel we have developed maturity is our project management systems. Our PMO works hard on supporting project managers with useful templates and documents, and evaluating their performance. The project control team reviens data gathered from diverse projects located in different cities. However, there appear to be some weaknesses here. For instance, as there are an overwbelming number of stakeholders on our projects, an effective method of managing communications has not been achieved. Actually the problem runs deeper than that. The lack of an effective method leads to overlooking important lessons that would help to improve future projects.

Recently, in order to increase the company's technical capabilities, we established an R๘D department that is working to minimise the downtime on our DC projects and use leading standard industry practices to satisfy auditors' requirements. This has proven very valuable to ensuring customer satisfaction.

Overall, I reckon we have to put more effort on building and developing our reputation within the industry, and controlling cost and time baselines to increase profit. I think that your approach to measuring our maturity is something we would like to continue to use, with your input and advice. We need to continually improve if we want to grow our current market share.

The CEO expressed high levels of satisfaction with both the method of maturity assessment and the practicality of its application in the office. The case study demonstrated that organisational strategy can be identified and capability can be demonstrated in terms of specific evidence collected during an independent audit. The outcome score provides a more precise measure of maturity than discrete hierarchical levels and involves up to 84 unique items of objective proof.

This case study highlights that maturity in the data centre infrastructure industry requires a set of capabilities that are somewhat different to what might be expected in other fields. For example, impact and environmental management are largely defined as relating to noise transfer to adjoining spaces and neighbouring properties. The firm scored well in terms of their investment in research and development (R\&D) which is seen as critical to firm growth and market share. A comprehensive human resource (HR) allocation system exists but has not been updated for many years. A 360-degree appraisal is carried out annually to measure team performance. Overall, the audit was able to make recommendations for improving system maturity, such as devoting more effort towards better communication protocols to support competitive advantage. In particular, some of the benefits of R\&D activity were not being captured and disseminated throughout the firm. Senior managers agreed that lessons learnt were not recorded in the PMO's system in a timely manner. Moreover, given the CEO manages the firm's portfolio himself, the assessor recommended that a team be established to handle this complex job in the near future.

MMM enables organisation maturity to be pursued via a customisable, systematic, strategic and practical approach. While it produces an overall score that can be used for internal trend analysis over time, the rigour of the process lies in the detailed assessment of individual capabilities. However, as capabilities are variables and organisation-specific, the model does not enable maturity to be compared across different organisations. Comparison is normally seen as a 
potential barrier to implementation in practice given that the maturity of an organisation (and hence the likelihood of achieving success in its endeavours) is not something to be broadcast to either the market or to one's competitors.

The approach used in MMM is facilitated by the involvement of experienced assessors. These assessors are critical in helping to realise the following benefits:

1. Identifying appropriate objectives and capabilities: These can be freely shared between organisations (via the assessors) since they reflect targets not performances

2. Certifying the self-assessment process: Evidence can be validated and audited by assessors to ensure probity

3. Recommendations to enhance protocols: An experienced assessor can suggest ways to address deficiencies and develop more mature systems to support business activities

Experienced assessors may be people who are already certifiers for other rival maturity models. It would be advantageous to use a small panel of assessors on every assessment. They are also likely to be drawn from senior project managers, directors of PMOs and qualified academics in the project management field. Their role includes auditing maturity evidence and providing advice on how to improve organisational systems and processes. International professional bodies such as PMI and IPMA, and national bodies such as APM and AIPM should act as brokers for putting organisations in touch with assessors, as well as ensuring assessors are appropriately trained.

\section{Conclusion}

The basis for achieving consistent excellence in project management is assisted by mature organisational systems and processes. MMM is a simple yet robust model capable of guiding the development of any project management environment that needs to support the business of successful project, program and/or portfolio delivery. It forms a bridge between organisational strategy and project success through compatibility with the PMBOK ${ }^{\mathrm{TM}}$ Guide and the 3D Integration Model for assessing optimal delivery of individual projects. It can be adopted as a self-assessment tool and enhanced by the employment of an experienced consultant or auditor to provide improvement advice. It is a potential replacement for the complex OPM3 tool especially for smaller organisations that cannot justify the resultant time and expense. MMM is the only maturity model that uses the PDCA continuous improvement cycle embedded in the PMBOK methodology, and the only maturity model that supports customisable organisational capabilities. Field-testing on a medium-sized firm in Tehran suggests the implementation of MMM in practice is feasible and considered valuable by organisational stakeholders. Despite established solutions like CMMI, P3M3 and OPM3, there is still opportunity for MMM to improve current practices.

A Microsoft Excel ${ }^{\mathrm{TM}}$ template for calculation of maturity scores is freely available from the lead author of this paper via an email request.

\section{References}

Allué, A., Domínguez, E., López, A. and Zapata, M.A. (2013) QRP: a CMMI appraisal tool for project quality management, Procedia Technology, 9, 664-669. doi: https://doi.org/10.1016/j.protcy.2013.12.073

Artto, K., Martinsuo, M., Gemünden, H.G. and Murtoaro, J. (2009) Foundations of program management: a bibliometric view, International Journal of Project Management, 27(1), 1-18. doi: https://doi.org/10.1016/j.ijproman.2007.10.007

Backlund, F., Chronéer, D. and Sundqvist, E. (2014) Project management maturity models - a critical review: a case study within Swedish engineering and construction organisations, Procedia Social and Behavioural Sciences, 119, 837-846. doi: https://doi.org/10.1016/j.sbspro.2014.03.094

Brookes, N. and Clark, R. (2009) Using maturity models to improve project management practice, POMS 20th Annual Conference, Florida USA, May. Available from: http://pomsmeetings.org/ConfProceedings/011/ FullPapers/011-0288.pdf 
Bullen, C.V. and Rockart, J.K. (1981) A primer on critical success factors, Boston: Center for Information Systems Research, MIT.

Cooke-Davies, T. (2002) The 'real' success factors on projects, International Journal of Project Management, 20(3), 185-190. doi : https://doi.org/10.1016/j.protcy.2013.12.073

Cooke-Davies, T. (2004) Project management maturity models, in Morris, P.W.G and Pinto, J.K., The Wiley Guide to Managing Projects, 1234-1255. doi: http://dx.doi.org/ 10.1016/S0263-7863(01)00067-9

Crawford, L. (2011) Fitting project management capability to strategy, 8th Annual Project Management Australia conference (PMOz): Project management at the speed of light, Sydney, Australia, 2-5 August. Available from: http://epublications.bond.edu.au/sustainable_development/122

Daniel, D.R. (1961) Management information crisis, Harvard Business Review, September-October.

Darwin, C. (1859) On the origin of species, London: John Murray.

Davis, K. (2014) Different stakeholder groups and their perceptions of project success, International Journal of Project Management, 32(2), 189-201. doi: https://doi.org/10.1016/j.ijproman.2013.02.006

de Souza, T.F. and Gomes, C.F.S. (2015) Assessment of maturity in project management: a bibliometric study of main models, Procedia Computer Science, 55, 92-101. doi:

https://doi.org/10.1016/j.procs.2015.07.012

Demir, C. and Kocabaş, İ. (2010) Project management maturity model (PMMM) in educational organisations, Procedia Social and Behavioral Sciences, 9, 1641-1645. doi: https://doi.org/10.1016/j.sbspro.2010.12.379

Dosi, G., Nelson, R.R. and Winter, S.G. (2000) The nature and dynamics of organisational capabilities, Oxford: Oxford University Press.

Drucker, P.F. (1954) The practice of management, New York: Harper \& Row.

Du, Q.L., Cao, S.M., Ba, L.L. and Cheng, J.M. (2008) Application of PDCA cycle in the performance management system, 4th International Conference on Wireless Communications, Networking and Mobile Computing, 2008 (WiCOM'08), IEEE, October, 1-4. doi: https://doi.org/10.1109/WiCom.2008.1682

Ebbesen, J.B. and Hope, A. (2013) Re-imagining the iron triangle: embedding sustainability into project constraints, PM World Journal, 2(III). Available from: http://nrl.northumbria.ac.uk/id/eprint/11311

Fahrenkrog, S., Abrams, F., Haeck, W. and Whelbourn, D. (2003) Project Management Institute's Organisational Project Management Maturity Model (OPM3), PMI North American Congress, Baltimore, MD, June.

Fernández-Sánchez, G. and Rodríguez-López, F. (2010) A methodology to identify sustainability indicators in construction project management: application to infrastructure projects in Spain, Ecological Indicators, 10(6), 1193-1201. doi: https://doi.org/10.1016/j.ecolind.2010.04.009

González, N., Marle, F. and Bocquet, J.C. (2007) Measuring project maturity: example in a French automotive organisation, International Conference on Engineering Design (ICED), August, 28-31. Available from: http://www.designsociety.org/downloadpublication/25671/measuring_project_maturity_example_in_a_french_automotive_organization

Hardgrave, B.C. and Armstrong, D.J. (2005) Software process improvement: it's a journey, not a destination, Communications of the ACM, 48(11), 93-96. doi: https://doi.org/10.1145/1096000.1096028

Hillson, D. (2003) Assessing organisational project management capability, Journal of Facilities Management, 2(3), 298-311. doi: https://doi.org/10.1108/14725960410808276

Hutson, N. (1997) What is project management?, The 28th Annual Project Management Institute 1997 Seminars \& Symposium, Chicago: Project Management Institute, 1141-1142.

Hwang, B.G. and Ng, W.J. (2013) Project management knowledge and skills for green construction: overcoming challenges, International Journal of Project Management, 31(2), 272-284. doi: https://doi.org/10.1016/j.ijproman.2012.05.004

Jiang, J.J., Klein, G., Hwang, H.G., Huang, J. and Hung, S.Y. (2004) An exploration of the relationship between software development process maturity and project performance, Information and Management, 41(3), 279-288. doi: https://doi.org/10.1016/S0378-7206(03)00052-1

Jin, D., Chai, K.H. and Tan, K.C. (2014) New service development maturity model, Managing Service Quality: An International Journal, 24(1), 86-116. doi: https://doi.org/10.1108/MSQ-10-2012-0134

Jugdev, K. and Thomas, J. (2002) Project management maturity models: the silver bullets of competitive advantage, Project Management Institute. Available from: http://hdl.handle.net/1880/44250

Kohlegger, M., Maier, R. and Thalmann, S. (2009) Understanding maturity models: results of a structured content analysis, IKNOW '09 and I-SEMANTICS '09, Graz, Austria, September, 51-61. Available from: http://iwi.uibk.ac.at/download/downloads/Publikationen/KMM.pdf

Langston, C. (2013) Development of generic key performance indicators for PMBOK using a 3D project integration model, Australasian Journal of Construction Economics and Building, 13(4), 78-91. doi: https://doi.org/10.5130/ajceb.v13i4.3658 (winner: 2016 PMAA Australian National Research Award; winner: 2016 IPMA Asia Pacific Regional Research Award; finalist: IPMA International Research Award) 
Lee, G. and Kwak, Y.H. (2012) An open government maturity model for social media-based public engagement, Government Information Quarterly, 29(4), 492-503. doi: https://doi.org/10.1016/j.giq.2012.06.001

Moen R. and Norman C. (2012) Evolution of the PDCA Cycle. Available from: www.pkpinc.com

Mullaly, M.E. and Thomas, J.L. (2010) Re-thinking project management maturity: perspectives gained from explorations of fit and value, PMI Research and Education Conference 2010: Defining the Future of Project Management, Pennsylvania: Project Management Institute.

Musat, D., Castaño, V., Calvo-Manzano, J.A. and Garbajosa, J. (2010) Mature: a model driven based tool to automatically generate a language that supports CMMI process areas specification, in Riel, A., O'Connor, R., Tichkiewitch, S. and Messnarz, R. (eds.), Systems, Software and Services Process Improvement, Springer, 48-59. doi: https://doi.org/10.1007/978-3-642-15666-3 5

Nandyal, R.S. (2003) People CMM: interpreting people CMM for software organisations, New Delhi: Tata McGrawHill Publishing Company Limited.

Nesensohn, C., Bryde, D., Ochieng, E. and Fearon, D. (2014) Maturity and maturity models in lean construction, Australasian Journal of Construction Economics and Building, 14(1), 45-59. doi: https://doi.org/10.5130/ajceb.v14i1.3641

Pane, E.S. and Sarno, R. (2015) Capability Maturity Model Integration (CMMI) for optimising object-oriented analysis and design (OOAD), Procedia Computer Science, 72, 40-48. doi: https://doi.org/10.1016/j.procs.2015.12.103

Pasian, B., Sankaran, S. and Boydell, S. (2012) Project management maturity: a critical analysis of existing and emergent factors, International Journal of Managing Projects in Business, 5(1), 146-157. doi: https://doi.org/10.1108/17538371211192946

Pinto J.A. and Williams N. (2013) Country project management maturity, 2013 PMI Global Congress Proceedings, Istanbul.

PMI (2013) Organisational Project Management Maturity Model (OPM3), Third Edition, Pennsylvania: Project Management Institute Inc.

Pretorius, S., Steyn, H. and Jordaan, J.C. (2012) Project management maturity and project management success in the engineering and construction industries in South Africa, South African Journal of Industrial Engineering, 23(3), 1-12. doi: https://doi.org/10.7166/23-3-507

Rockart, J.F. (1979) Chief Executives Define their Own Data Needs, Sussex Business Review, March-April.

Shewhart, W.A. (1939) Statistical method from the viewpoint of quality control, Washington: U.S. Department of Agriculture.

Silva, D., Tereso, A., Fernandes, G. and Pinto, J.Â. (2014) OPM3 Portugal project: analysis of preliminary results, Procedia Technology, 16, 1027-1036. doi: https://doi.org/10.1016/j.protcy.2014.10.057

Sowden, R., Hinley, D. and Clarke, S. (2008) Portfolio, Programme \& Project Management Maturity Model (P3M3), Office of Government Commerce Journal, 1-4.

Stacey, R.D. (2003) The learning organisation. In: Stacey, R.D. Strategic Management and Organisational Dynamics, Harlow: Pearson Education Ltd, 103-128.

Staples, M. and Niazi, M. (2010) Two case studies on small enterprise motivation and readiness for CMMI, 11th International Conference on Product Focused Software, June, 63-66. doi: https://doi.org/10.1145/1961258.1961274

Staples, M., Niazi, M., Jeffery, R., Abrahams, A., Byatt, P. and Murphy, R. (2007) An exploratory study of why organisations do not adopt CMMI, Journal of Systems and Software, 80(6), 883-895. doi: https://doi.org/10.1016/j.jss.2006.09.008

Thomas, J.L. and Mullaly, M.E. (2008) Researching the value of project management, Pennsylvania: Project Management Institute.

Westerveld, E. (2003) The Project Excellence Model: linking success criteria and critical success factors, International Journal of Project Management, 21(6), 411-418. doi: https:/ / doi.org/10.1016/S0263-7863(02)00112-6

Wood, J.C. and Wood, M.C. (2005) W. Edwards Deming: critical evaluations in business and management (Volume 1), Routledge.

Wysocki, R.K. (2004) Project management process improvement, Artech House.

Ye, H., Song, Z. and Sun, Q. (2014) Design of green data centre deployment model based on cloud computing and TIA942 heat dissipation standard, IEEE Workshop on Electronics, Computer and Applications, May, 433-437. doi: https://doi.org/10.1109/IWECA.2014.6845649

Young, M., Young, R. and Romero Zapata, J. (2014) Project, programme and portfolio maturity: a case study of Australian Federal Government, International Journal of Managing Projects in Business, 7(2), 215-230. doi: https://doi.org/10.1108/IJMPB-08-2013-0034 